\title{
The Effect of Tocolysis by Oral Nefidipine on Doppler Velocimetry of Umbilical, Middle Cerebral Arteries and Ductus Venosus
}

\author{
ALAA EL-DIN A. EL-GUINDY, M.D.*; MOHAMMED A. EL-KADY, M.D.*; \\ AMR M.A. EL-HELALY, M.D.* and AHMED M. SALAH, M.Sc.**
}

The Department of Obstetrics \& Gynecology, Faculty of Medicine, Ain Shams University*, Cairo and El-Minia General Hospital**, El-Minia, Egypt

\begin{abstract}
Aim of Work: To assess effect of nifedipine administration as a tocolytic agent on placental and fetal cerebral blood flow as well as on fetal cardiac function by measuring Pulsatility Index (PI) of the umbilical artery, Middle Cerebral Arteries (MCA) and Ductus Venosus (DV) twice, immediately before initial nifedipine dose and 24 hours after the therapy.

Methods: Prospective, observational, analytic cohort, clinical trial involved 70 women with single viable fetus between 24-35 weeks undergoing tocolysis by nifedipine. Pulsatility Index (PI) of the umbilical artery, Middle Cerebral Arteries (MCA) and Ductus Venosus (DV) was assessed twice, immediately before initial nifedipine dose and 24 hours after the therapy.

Results: The mean age of pregnant participants was (28.6 \pm $3.1)$, mean Body Mass Index (BMI) was (22.2 \pm 1.3$)$. There was no significant effect of nifedipine on Hemodynamic parameters (maternal heart rate, systolic blood pressure and diastolic blood pressure). There was no statistically significant difference of Pulsatility Index (PI) of the umbilical artery, Middle Cerebral Arteries (MCA) and Ductus Venosus (DV) before and after treatment.

Conclusion: Oral nifedipine is a safe tocolytic agent on placental and fetal cerebral blood flow as well as on fetal cardiac function when used in pregnant women at risk of preterm delivery during the first 24 hours.
\end{abstract}

Key Words: Tocolysis - Nifedipine therapy - Doppler velocimetry - Umbilical - Middle cerebral arteries Ductus venosus.

\section{Introduction}

PRETERM birth, also known as premature birth or delivery, is defined by the World Health Organisation (WHO) as the delivery of babies who are born, alive, before 37 weeks of gestation [1] .

Correspondence to: Dr. Alaa El-Din A. El-Guindy, The Department of Obstetrics \& Gynecology, Faculty of Medicine, Ain Shams University, Cairo
Preterm birth has a significant morbidity and mortality on the new born. The severity of these effects increases the more premature the delivery is. Approximately, $50 \%$ of all perinatal deaths are caused by preterm delivery, with those surviving often suffering from afflictions, caused by the birth $\left[{ }^{2}\right]$.

As antenatal corticosteroids reduce morbidity and mortality, so delaying preterm delivery by tocolytic therapy is an important intervention in obstetrics. Although tocolytics do not improve neonatal outcomes, they can delay preterm delivery long enough to administer antenatal corticosteroids or to transfer the mother to a tertiary care facility $[3,4]$.

Although several drugs that inhibit pre-term contractions (tocolytics) are available, the pharmacotherapy of PTB is inappropriate. There is a great need for effective and well-tolerated drugs against PTB as high doses of tocolytics lead to maternal and fetal side-effects which in turn induce further complication. $\mathrm{Ca} 2+$ Channel Blockers (CCBs), and especially nifedipine and nicardipine are used frequently for tocolysis and They are more significantly effective than traditional tocolytics such as beta-adrenergic receptor ( $\beta$-AR) blockers or magnesium sulphate. Even though calcium channel blockers do not meet the criteria of ideal tocolytics, they have certain criteria that make them preferable to other tocolytics [5].

Although animal studies found that administration of calcium channel blockers may cause impaired uterine blood flow that may lead to fetal hypoxemia and academia [6,7], studies in human pregnancies could not confirm these harmful effects $[8,9]$. 


\section{Subjects and Methods}

This study was prospective, observational, analytic cohort, clinical trial conducted at AinShams University Maternity Hospital in period from March 2015 to March 2017.

In 70 women with single viable fetus between 24-35 weeks tocolysis was undergone by nifedipine. Pulsatility Index (PI) of the umbilical artery, Middle Cerebral Arteries (MCA) and Ductus Venosus (DV) was assessed twice, immediately before initial nifedipine dose and 24 hours after the therapy.

The patients were recruited from women attending emergency ward suffering from threatened preterm labour.

All cases was subjected to the following inclusion and exclusion crieteria:

\section{Inclusion criteria:}

- Pregnant with a single fetus of 24-35 weeks' gestation.

- Threatened preterm labour which is defined as clinical criteria of regular uterine contractions accompanied by a change in cervical dilation, effacement, or both or initial presentation with regular contractions and cervical dilation of at least $2 \mathrm{~cm}$. (ACOG, 2012).

\section{Exclusion criteria:}

- Maternal medical disorders such as heart or lung disease, high blood pressure, diabetes or pre-eclampsia.

- Premature rupture of membranes.

- Chorioamnionitis.

- Intrauterine growth restriction.

- Acute fetal distress.

- Fetal malformations.

- Clinical diagnosis of (partial) placental abruption.

\section{Outcomes:}

Placental and Fetal Doppler Parameters before and 24 hours after nefidipine administration.

After taking informed written consent approved from ethical committee, the recruited patients were subjected to detailed history taking general, abdominal and local examination. Complete blood count and pelvic ultrasound were done to every case and the decision of tocolysis by oral nefidipine was taken by the consultant on duty.

Afterwards, nifedipine was administered as an initial oral dose of $10 \mathrm{mg}$ repeated at every $15 \mathrm{~min}$ to a maximum dose of $40 \mathrm{mg}$. If contraction subsides the maintenance dose became $20 \mathrm{mg}$ per os/ 8 hours for 24 hours [10].

Doppler velocimetry; Pulsatility Index (PI) of the umbilical artery, Middle Cerebral Arteries (MCA) and Ductus Venosus (DV) were performed twice, immediately before initial nifedipine dose and after 24 hours of therapy at Ain-Shams University fetal medicine unit using a Medison Samsung R5.

Examinations was done with the patients in the semi-sitting position, with scanning during fetal quiescence without uterine contractions. We measured each vessel twice, and then the mean value was recorded.

We used a triplex system (two-dimensional image, color Doppler and pulsatile Doppler) with color mapping equipped with a $2-8 \mathrm{MHz}$ convex transducer to obtain Blood flow. Low-frequency $(100 \mathrm{~Hz})$ filters was used to minimize the possibility of error due to movement of the vascular walls. Scans with a minimum of six uniform waves were analyzed. The sample volume size was adjusted according to the diameter of the vessel to be studied and the angle of insonation was kept as close to $0^{\circ}$ as possible. When a good signal was obtained, the image was frozen and the Doppler flow velocimetry parameters was automatically provided by the equipment's software.

The umbilical artery was examined first followed by MCA and ductus venosus. For the umbilical artery, velocimetry were carried out at the midpoint between the placental and abdominal insertions of the vessel.

For studies of the MCA, the circle of Willis will be localized with color Doppler according to the method described by Arbeille et al., and the Doppler gate was placed on the MCA close to its origin from the internal carotid artery. The insonation angle was kept as close to zero as possible, typically within $+15^{\circ}$ [11]

Ductus venosus Doppler waveforms was obtained from a transverse view of the fetal abdomen at the same anatomic plane of the abdominal circumference. By superimposing color flow Doppler to the gray-scale image, the ductus venosus can be identified as it branches from the umbilical vein. Turbulence is commonly seen within the ductus venosus given its narrow lumen. The presence of turbulence on color flow Doppler helps in identifying the ductus venosus. Ductus venosus 
Doppler waveforms are biphasic in shape, with the first phase corresponding to ventricular systole, the second phase to early diastole, and the nadir of the second phase to late diastole or the atrial kick.

\section{Statistical analysis:}

The collected data were coded, tabulated, and statistically analyzed using IBM SPSS statistics (Statistical Package for Social Sciences) software Version 22.0, IBM Corp., Chicago, USA, 2013.

Descriptive statistics were done for quantitative data as minimum and maximum of the range as well as mean \pm SD (standard deviation) for quantitative normally distributed data, while it was done for qualitative data as number and percentage.

Inferential analyses were done using $95 \%$ confidence interval $(\mathrm{C} \%)$ and paired $t$-test in cases of two dependent groups for quantitative variables using with normally distributed data. The level of significance was taken at $p$-value $<0.050$ is significant, otherwise is non-significant.

\section{Results}

Table (1) showed that the mean age of pregnant participants was (28.6 \pm 3.1$)$, mean Body Mass Index (BMI) was (22.2 \pm 1.3$)$, parity was ranging between primigravida and 4 parity and for gestational age the mean was $(29.8 \pm 2.5)$ weeks.

Table (2) showed that there was no significant effect of nifedipine on hemodynamic parameters (maternal heart rate, systolic blood pressure and diastolic blood pressure).

Concerning maternal complications among the studied cases there was headache 2 cases $2.9 \%$ and flushing 4 cases $5.7 \%$ and no other maternal complications recorded.

Table (3) showed that there was no significant differences in Pulsatility Index (PI) of the umbilical artery, Middle Cerebral Arteries (MCA) and Ductus Venosus (DV) before initial nifedipine dose and 24 hours after the therapy.

Table (1): Demographic characteristics of the studied cases.

\begin{tabular}{lcl}
\hline Variables & Mean \pm SD & Range \\
\hline Age (years) & $28.6 \pm 3.1$ & $22.0-36.0$ \\
BMI $\left(\mathrm{Kg} / \mathrm{m}^{2}\right)$ & $22.2 \pm 1.3$ & $18.2-24.9$ \\
Parity & $1.9 \pm 1.2$ & $0.0-4.0$ \\
GA (weeks) & $29.8 \pm 2.5$ & $24.0-34.0$ \\
\hline
\end{tabular}

Total $=70$.
Table (2): Maternal hemodynamic variables of the studied group before and after treatment.

\begin{tabular}{lccc}
\hline & $\begin{array}{c}\text { Before ttt } \\
\text { Mean } \pm \text { SD }\end{array}$ & $\begin{array}{c}\text { After ttt } \\
\text { Mean } \pm \text { SD }\end{array}$ & $\begin{array}{c}p \text { - } \\
\text { value }\end{array}$ \\
\hline - Maternal heart rate (bpm) & $75.1 \pm 4.0$ & $76.2 \pm 4.2$ & 0.062 \\
- Maternal systolic blood & $117.7 \pm 5.0$ & $116.2 \pm 5.5$ & 0.064 \\
$\begin{array}{l}\text { pressure (mm Hg) } \\
\text { - Maternal diastolic blood } \\
\text { pressure (mm Hg) }\end{array}$ & $72.8 \pm 4.6$ & $71.4 \pm 5.0$ & 0.064 \\
\hline
\end{tabular}

Table (3): Pulsatility Indices (PI) of the umbilical artery, Middle Cerebral Artery (MCA) and ductus venosus of the studied group before and after treatment.

\begin{tabular}{lccc}
\hline & $\begin{array}{c}\text { Before } \\
\mathrm{ttt}\end{array}$ & $\begin{array}{c}\text { After } \\
\mathrm{ttt}\end{array}$ & $\begin{array}{c}p \text { - } \\
\text { value }\end{array}$ \\
\hline - Umbilical Artery PI & $0.97 \pm 0.04$ & $0.96 \pm 0.04$ & 0.145 \\
- Middle Cerebral Artery & $1.97 \pm 0.15$ & $1.95 \pm 0.12$ & 0.242 \\
$\quad$ PI & & & \\
- Ductus venosus PI & $0.75 \pm 0.02$ & $0.74 \pm 0.02$ & 0.073 \\
\hline
\end{tabular}

\section{Discussion}

Hemodynamic conditions are particulary different during pregnancy. Animal studies showed conflicting data about circulatory system changes after nifedipine. Harake et al., results showed reduction of uterine blood flow and oxygen content in fetal blood in instrumented pregnant sheep with intravenous nifedipine administration [7]. Blea et al., used nifedipine doses similar to those used in humans. They found the evidence of hypoxia and acidosis in the sheep fetus [12]. No changes in maternal and placental compartments were detected. In Holbrook's et al., research, a single bolus of another calcium channel blocker, nicardipine, was administered to instrumented sheep and no alteration in uterine and fetal arterial blood flow were observed [13].

In our study no statistical significant differences were found in Pulsatility Index (PI) of the umbilical artery, Middle Cerebral Arteries (MCA) and Ductus Venosus (DV) before initial nifedipine dose and 24 hours after the therapy which confirm safety of nifedipine on placental and fetal cerebral blood flow as well as on fetal cardiac function when used in pregnant women at risk of preterm delivery.

Our results similar to many studies evaluated effect of nifedipine on maternal and fetal circulation and found no significant difference in Pulsatility Index (PI) of the umbilical artery [14-18] or (MCA) Middle Cerebral Arteries [15,17,18]

In Abdel Hak and Gafaar, study which was a prospective observational study involved 30 preg- 
nant women with a single fetus of 30-34 weeks' gestation undergoing tocolysis with nifedipine as an initial sublingual dose of $20 \mathrm{mg}$ repeated at every $20 \mathrm{~min}$ to a maximum dose of $60 \mathrm{mg}$. Then the maintenance dose was oral $20 \mathrm{mg} / 6$ hours for 24 hours. Pulsatility Index (PI) of the umbilical artery, Middle Cerebral Arteries (MCA) and Ductus Venosus (DV) were assessed before initial nifedipine dose and after 24 hours of therapy. Thier results showed that no significant difference in umbilical artery pulsatility indices before treatment $(0.98 \pm$ $0.05)$ and at 24 hours after treatment $(0.97 \pm 0.01)$ with $p$-value $=0.399$ and that results match with the results of our study [20]

Regarding Pulsatility Index (PI) of the Middle Cerebral Artery (MCA) and Ductus Venosus (DV) there was significant difference in both middle cerebral artery pulsatility indices before treatment $(1.99 \pm 0.17)$ and at 24 hours after treatment (1.86 \pm $0.08)$ with $p$-value $=0.002$ and ductus venosus before treatment $(0.84 \pm 0.07)$ and at 24 hours after treatment $(0.82 \pm 0.07)$ with $p$-value $=0.000$ and this mismatch with results of our but they found that this difference in Middle Cerebral Artery (MCA) and ductus venosus pulsatility indices was within the clinical acceptable levels and had no clinical significance and they concluded that Nifedipine tocolytic therapy is safe on maternal cardiovascular system and fetal circulatory status up to 24 hours after starting therapy [20].

In Lima et al., study which was a prospective, observational, analytic cohort study performed in 47 pregnant women undergoing nifedipine tocolysis. Doppler assessment of uterine, umbilical and fetal middle cerebral (MCA) arteries was performed before and 5 and 24h after an initial 20-mg sublingual dose, which was repeated twice at 20-min intervals and The maintenance dose consisted of $20 \mathrm{mg}$ orally every $6 \mathrm{~h}$ for $24 \mathrm{~h}$ up to a total of 100 $120 \mathrm{mg}$ nifedipine. They measured resistance index and his results showed that no significant difference in umbilical artery resistance indices before treatment $(0.61 \pm 0.06)$, at 5 hours $(0.60 \pm 0.06)$ and at 24 hours after treatment $(0.59 \pm 0.06)$ with $p$-value $=0.160$ and that results match with the results of our study [21].

Regarding Middle Cerebral (MCA) arteries resistance index they found significant difference before treatment $(0.85 \pm 0.04)$, at 5 hours $(0.85 \pm 0.04)$ and at 24 hours after treatment $(0.81 \pm 0.06)$ with $p$-value $=0.001$ and that results mismatch with the results of our study. They also measured also measured the MCA to umbilical artery RI ratio before and after tocolysis with oral nifedipine; this ratio is a well-known marker of fetal wellbeing. No changes were observed, thus indicating that no inversion occurred in the ratio, despite the reduction in the resistance of the MCA. Thus they suggested that alterations in Doppler flow velocimetry indices in the middle cerebral artery after tocolysis with oral nifedipine may not result in any fetal repercussions [21]

In Guclu et al., study number of patients for whom nifedipine treatment was used as a tocolytic therapy for preterm labor were 28 . Nifedipine therapy was initiated with a 10-mg capsule sublingually and if uterine contractions persisted after $15 \mathrm{~min}$, another doses of $10 \mathrm{mg}$ was given up to a maximum dose of $40 \mathrm{mg}$ nifedipine and a maintenance dose of $80-120 \mathrm{mg}$ nifedipine daily was given. They measured Doppler waveforms of uterine, umbilical and middle cerebral (MCA) arteries before, 12 hours, 24 hours and 48 hours after the first dose. Their results showed that no significant difference in umbilical artery pulsatility indices before treatment $(1.02 \pm 0.03)$, at 12 hours $(1.0 \pm$ $0.03), 24$ hours $(1.03 \pm 0.02)$ and at 48 hours after the first dose $(1.03 \pm 0.02)$, with $p$-value $=0.43$ and that results match with the results of this study.

Regarding middle cerebral (MCA) arteries resistance index they found significant difference before treatment $(2.01 \pm 0.05)$, at 12 hours $(1.99 \pm$ $0.04), 24$ hours $(1.90 \pm 0.04)$ and at 48 hours after the first dose $(1.86 \pm 0.04)$, with $p-<0.01$ and that results mismatch with the results of this study. The possible explanation of their results may be small sample size as only 28 patients were enrolled in their study versus 70 in our study.

So we can conclude that oral nifedipine is a safe tocolytic agent on placental and fetal cerebral blood flow as well as on fetal cardiac function when used in pregnant women at risk of preterm delivery during the first 24 hours but further studies evaluating different dosages of nifedipine to detect the best lower, effective and safe dose may be recommended.

\section{References}

1- WHO. Born too soon: The Global Action Report on preterm birth, 2012.

2- BAKER P.N. and KENNY L.: Obstetrics by Ten Teachers. Hodder Arnold Press, 436 p, 2011.

3- HAAS D.M., IMPERIALE T.F., KIRKPATRICK P.R., KLEIN R.W., ZOLLINGER T.W. and GOLICHOWSKI A.M.: Tocolytic therapy: A meta-analysis and decision analysis. Obset. Gynecol., 113: 585-94, 2009. 
4- ROBERTS D. and DALZIEL S.R.: Antenatal corticosteroids for accelerating fetal lung maturation for women at risk of preterm birth. Cochrane Database Syst. Rev., 3: CD004454, 2006.

5- GÁSPÁR R.1. and HAJAGOS-TÓTH J.: Calcium Channel Blockers as Tocolytics: Principles of Their Actions, Adverse Effects and Therapeutic Combinations. Pharmaceuticals, 6: 689-99, 2013.

6- DUCSAY C.A., THOMPSON J.S., WU A.T. and NOVY M.: Effects of calcium entry blocker (nicardipine) tocolysis in rhesus macaques: Fetal plasma concentrations and cardiorespiratory changes. Am. J. Obstet. Gynecol., 157: 1482-6, 1987.

7- HARAKE B., GILBERT R.D., ASHWAL S. and POWER G.G.: Nifedipine: Effects on fetal and maternal hemodynamics in pregnant sheep. Am. J. Obstet. Gynecol., 157: 1003-8, 1987.

8- MONGA M. and CREASY R.K.: Pharmacologic management of preterm labor. Semin. Perinatol., 19: 84-96, 1995.

9- GUCLU S., SAYGILI U., DOGAN E., DEMIR N. and BASCHAT A.A.: The short-term effect of nifedipine tocolysis on placental, fetal cerebral and atrioventricular Doppler waveforms. Ultrasound Obstet. Gynecol., 24 (7): 761-5, 2004.

10- KING J.F., FLENADY V.J., PAPATSONIS D.N., DEKKER G.A. and CARBONNE B.: Calcium channel blockers for inhibiting preterm labor. Cochrane Database Syst. Rev., CD002255, 2002.

11- ARBEILLE P., BODY G., FIGNON A., SALIBA E., TRANQUART F. and POURCELOT L.: Doppler assessment of the intracerebral circulation of the fetus. Clin. Phys. Physiol. Meas., 10 (Suppl A): 51-7, 1989.

12- BLEA C.W., BARNARD J.M., MAGNESS R.R., PHERNETTON T.M. and HENDRICKS S.K.: Effect of nifedipine on fetal and maternal hemodynamics and blood gases in the pregnant ewe. Am. J. Obstet. Gynecol., 176: 922-30, 1997.

13- HOLBROOK R.H. Jr., VOSS E.M. and GIBSON R.N.:
Ovine fetal cardiorespiratory response to nicardipine. Am. J. Obstet. Gynecol., 161: 718-21, 1989.

14- KARAHANOGLU E., ALTINBOGA O., AKPINAR F., DEMIRDAG E., OZDEMIRCI S., AKYOL A. and YALVAC S.: Nifedipine increases fetoplacental perfusion. J. Perinat. Med., 45: 51-5, 2017.

15- BAYKAL B.Ö. and AVCiO GLU S.N.: Comparison of effects of nifedipine and ritodrine on maternal and fetal blood flow patterns in preterm labor. J. Turk. Ger. Gynecol. Assoc., 16: 80-5, 2015.

16- ULUBA SOGLU H., BAYAR Ü.O., KAYA C. and UNGAN B.: The effect of nifedipine tocolysis on Doppler indices of the uterine and umbilical arteries. J. Clin. Ultrasound., 43: 322-6, 2015.

17- GREZESAK M., AHMED R.B. and WILCZYNSKI J. 48 hours administration of nifedipine in spontaneous preterm labour-Doppler blood flow assessment of placental and fetal circulation. Neuro. Endocrinol. Lett., 34: 68792, 2013.

18- GUCLU S., SAYGILI U., DOGAN E., DEMIR N. and BASCHAT A.A.: The short-term effect of nifedipine tocolysis on placental, fetal cerebral and atrioventricular Doppler waveforms. Ultrasound Obstet. Gynecol., 24: 761-5, 2004.

19- GUCLU S., GOL M., SAYGILI U., DEMIR N., SEZER O. and BASCHAT A.A.: Nifedipine therapy for preterm labor: Effects on placental, fetal cerebral and atrioventricular Doppler parameters in the first 48 hours. Ultrasound Obstet. Gynecol., 27 (4): 403-8, 2006.

20- ABDEL HAK A.M. and GAFAAR H.M.: Effects of nifedipine therapy for preterm labour on placental and fetal doppler parameters in the first 24 hours. Med. J. Cairo Univ., 79: 335-40, 2011.

21- LIMA M.M. De S., SOUZA A.S.R., DINIZ C., PORTO A.M.F., AMORIM M.M.R. and MORON A.F.: Doppler velocimetry of the uterine, umbilical and fetal middle cerebral arteries in pregnant women undergoing tocolysis with oral nifedipine. Ultrasound Obstet. Gynecol., 34: 311-5, 2009. 


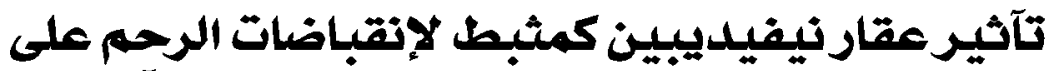

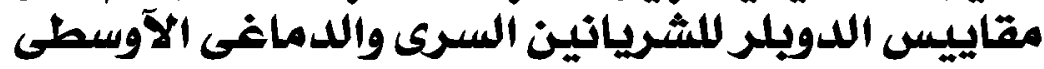 والقناة الوريدية اليرية}

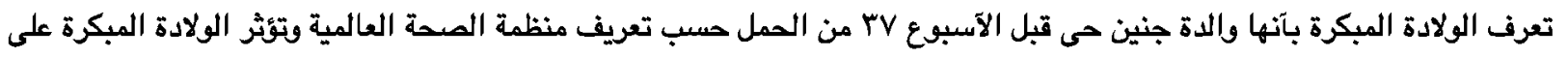

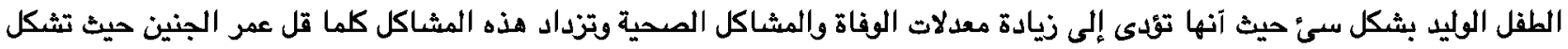

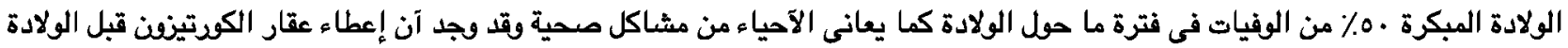

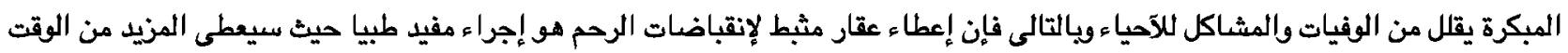

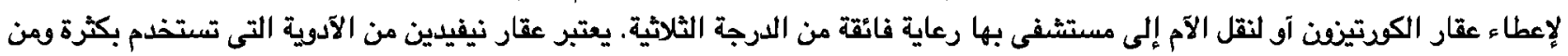

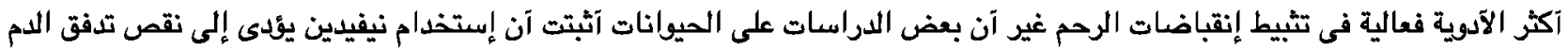

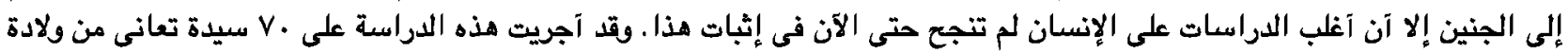

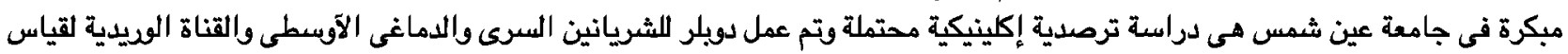

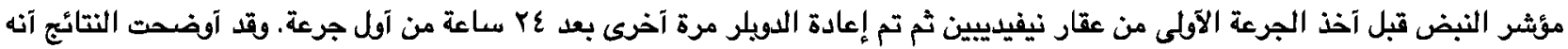

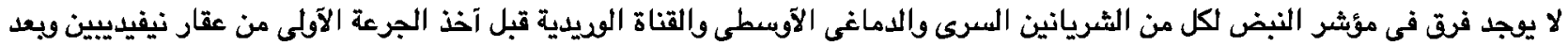

